\title{
LETTERS
}

\section{Don't forget peripheral arterial disease in diabetic foot osteomyelitis}

Drs. Mutluoglu and Lipsky provide five things to know about an important and common affliction that can lead to severe illness and limb loss. ${ }^{1}$ Number six should be to assess for peripheral arterial disease.

Ankle brachial index measurements are often falsely elevated (and so can appear falsely reassuring) in patients with diabetes. If you cannot confidently palpate pedal pulses, please call a vascular surgeon.

\section{Dion L. Davidson MD}

Vascular surgeon, Valley Regional Hospital, Kentville, NS

- Cite as: CMAJ 2017 March 6;189:E374. doi: 10.1503/cmaj.732589

\section{Reference}

1. Mutluoglu M, Lipsky BA. Diabetic foot osteomyelitis. CMAJ 2016;188:E535.

Competing interests: None declared. 